\title{
Robofest - A Playful Learning Environment Through Autonomous Robotics
}

\author{
Chan-Jin Chung
}

Founder \& Director of Robofest, Lawrence Technological University, Michican, USA

\begin{abstract}
Robofest [1, 2, 3] is a student centered indoor autonomous robotics competition based on PBL (Problem-Based Learning) [4] and CBL (Competition-Based Learning) [5] paradigms. Its primary mission is to generate excitement \& interest among young people for Science, Technology, Engineering, and Mathematics (STEM) through robotics projects integrating STEM subjects and Computer Science. Secondly, Robofest provides playful environment for students to develop well-rounded core value skills such as teamwork, leadership, creativity/entrepreneurship, communication and problem solving skills. Our third mission is to prepare youth to excel in higher education and technological careers for the future.
\end{abstract}

Keywords: Robofest, Problem-Based Learning, Competition-Based Learning, STEM, STEaM, RoboParade, RoboArts, Unknown Mission Challenge, BottleSumo, Vision Centric Challenge, Game

\section{What Makes Robofest Unique?}

Students must fully program their robots to perform their missions without human assistance. No joysticks or remote controls are allowed. In order to let robot think \& make decisions itself in a dynamic \& (partly) unknown environment, students must think harder to consider all possible cases of robot behaviors, which promotes students' effective learning in computer science and multiple STEM subjects.

Most Robofest competitions are like robotics hands-on exams. Unknown tasks and unknown competition field factors are unveiled at the beginning of the competition. The idea of unknowns was first introduced in 2003. No communication with coaches or parents is allowed during competitions. Students instantly design, construct, and program the robots and make all decisions during competitions to solve the unveiled problems. Because of the unknown problems and factors, adult mentors and coaches realize that they have to teach their students to solve problems by themselves.

Robofest is one of the most affordable autonomous robotics competitions in the world with minimal registration fees. Instead of requiring branded materials, any type of robot kit, materials, actuators, and sensors are allowed. Robots can be programmed with any programming language. Reusing parts and old kits is encouraged.

All registered participants receive medals and personalized certificates. Winners of the qualifying and championship rounds receive trophies. Each team member's name of the winning team at the World Championship is published on the web.

Robofest offers a wide variety of competition categories that fit multiple experience levels, interests, and learning styles.
The most popular category is Game where teams compete to accomplish missions putting math skills to the test, using fully autonomous robots. Unknown tasks and factors are unveiled to solve in 30 minutes.

Exhibition is like robotics science fair. Students have total freedom to show off any autonomous robotics project. A panel of Judges selects winners based on a rubric.

In Vision Centric Challenge (Vcc), teams develop robots with cameras to maneuver through an obstacle course or maps representing data structures such as lists, trees or graphs. Various shapes are used to represent nodes of the map. This advanced challenge is for college and high school students.

In BottleSumo comptitions, Robots vie to intentionally push a bottle off a table or to be the last robot remaining on the table. This challenge is for beginners.

Mission tasks are completely unknown in Unknown Mission Challenge (UMC) until the day of competition, so students must develop problem-solving skills on the fly. The level of this category is Intermediate-Advanced.

In RoboParade [9], elaborately decorated, robotic floats autonomously parade along a route in a colorful, creative display. This program is for beginners.

Robots perform dance, play music, and/or make/paint shapes/patterns in Intermediate-Advanced level RoboArts category.

In Game, BottleSumo, and Vcc, challenge problems are defined by Robofest and given to students. However, in Exhibition and RoboArts each student team defines project problems to solve. 
They can be viewed as perfect examples of self-directed learning (SDL) [4]. RoboParade is a hybrid category where some required tasks are predefined by Robofest and each team add its own problems to solve. Characteristics of the above seven Robofest competition categories are summarized in Table 1 below.

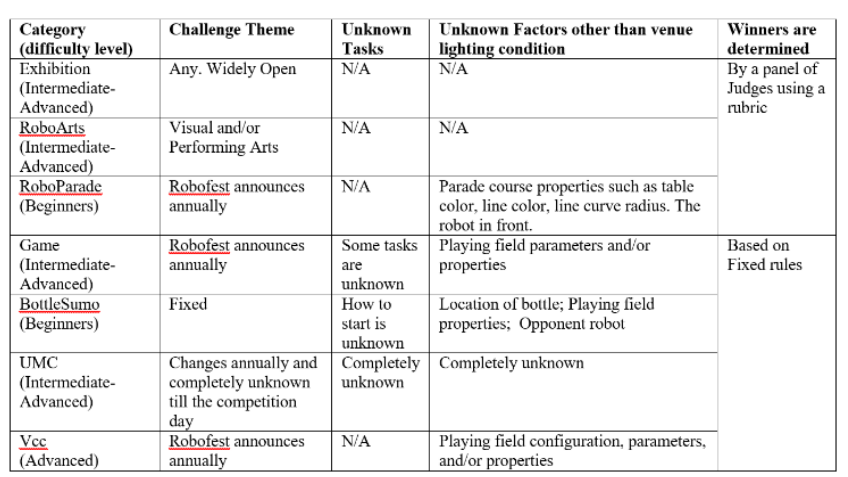

Table 1. Robofest Competition Categories and their characteristics

\section{Historical aspect of Robofest Categories}

When Robofest launched in 1999-2000 academic year, 3 Games with fixed rules were offered to teams. However, Games with fixed rules have limitations as a learning tool. If rules are fixed, even though there are some rooms for students to innovate and be creative within the domain of the contest rules, students are not being asked to think more broadly. To address this pedagogical issue and to implement self-directed learning (SDL) environment, a new category called "Exhibition" was launched in 2001-2002 year.

In 2002-2003 year, we introduced unknown tasks that students must program at the team tables without any adults' help. How to start the robot was unknown. This was needed, since parental involvement of some teams was too much.

In order to provide integrated STEAM (Science, Technology, Engineering, Arts, and Mathematics) or TEAMS (Technology, Engineering, Arts, Mathematics, and Science) learning opportunities with added art component through robotics, in 2006-2007 year, we started RoboParade and RoboFashion \& Dance Show categories. Later in 2013, RoboFashion \& Dance Show category was merged to GRAF (Global Robotics Art Festival) [8]. Later, GRAF is renamed to RoboArts in 2007.

Unknown Mission Challenge (UMC) was launched in 20132014 year. The goal of the challenge is to provide a complete student-centered opportunity to develop problem-solving skills on the fly without any external help from adult coaches.

Inspired by DARPA Urban Challenge, in 2006-2007 academic year, Mini Urban Challenge was started using vision only platform called L2Bots. Later in 2009-2010 year, the competition name became Vcc.

In order to attract more students and to provide a category for beginners, traditional robot sumo category was offered in 20062007 year. An extended version of robot sumo game called BottleSumo was created in 2010.
WISER (World conference on Integrated STEaM Education through Robotics) was kicked off in 2014. The main goals of mini conference for students, teachers, coaches, and parents are to share experiences/knowledge and exchange ideas in Robotics education for the effective STEaM learning environment. Additional goals are to discuss and research how to advance robotics education and educational robotics ultimately for humanity through STEaM learning paradigms.

\section{Some Historical Robofest Data}

The average Robofest team size in 2019 was 3.0 and the average number of students per team size since 2000 is 3.3. This small team size is good for effective learning, because each student has more opportunities to contribute to the team's objectives. Figure 1 shows the number of student participants since 2000. The cumulative number of registered students and teams in our web database since 2000 has reached 28,365.

Robofest competitions can be generalized into two categories: Games that use fixed rules (including BottleSumo, Vision Centric Challenge, and Unknown Mission Challenge) and open-ended style that has no or a few fixed rules (including Exhibition, RoboParade and RoboArts). In open-ended style competitions, winners are decide by a panel of Judges using a rubric. Figure 2 shows the trend of number of teams between Games and Exhibition since 2005. We can see that the participation in the open-ended exhibition style categories was slightly decreased in $2019.76 \%$ teams participated in Game style, whereas $24 \%$ teams did in Exhibition style competitions.

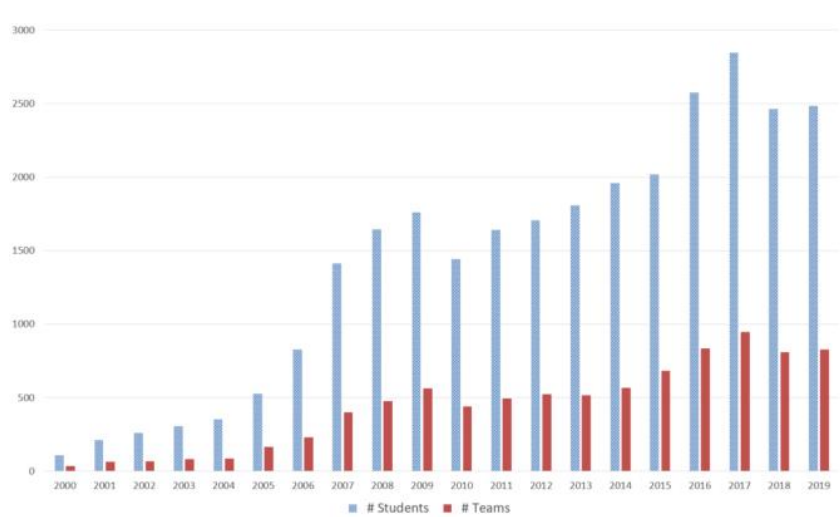

Figure 1. Number of Robofest Student Participants and Teams Since 2000

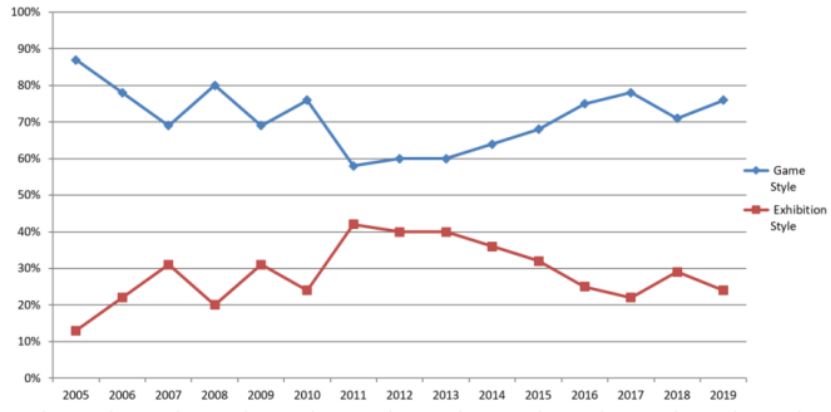

Figure 2. Percentages of Game style teams and Exhibition style teams

Regarding gender, Robofest is female-student-friendly. In $2019,71 \%$ were male and $29 \%$ were female students. Figure 3 
shows the gender ratios of Robofest students. The average since 2005 had been $74 \%$ male and $26 \%$ female.

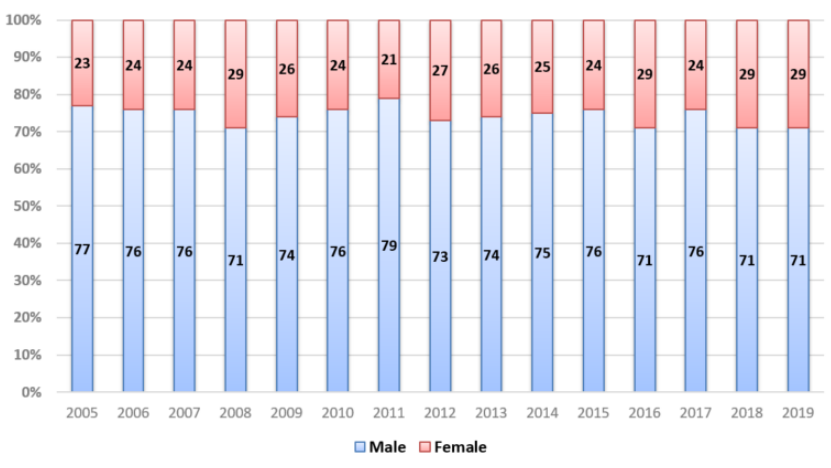

Figure 3. Gender Ratios of Robofest Students

Robofest's primary mission is to generate excitement \& interest among young people for STEM subjects and careers. Increased numbers of students expressed that they would now consider a career involving STEM after their Robofest exposure. Pre and post survey results since 2014 are shown in Figure 4. For example in 2018, 80.4\% students were considering STEM careers before particiating Robofest. After participating in Robofest, the percentage increased to $87.2 \%$.

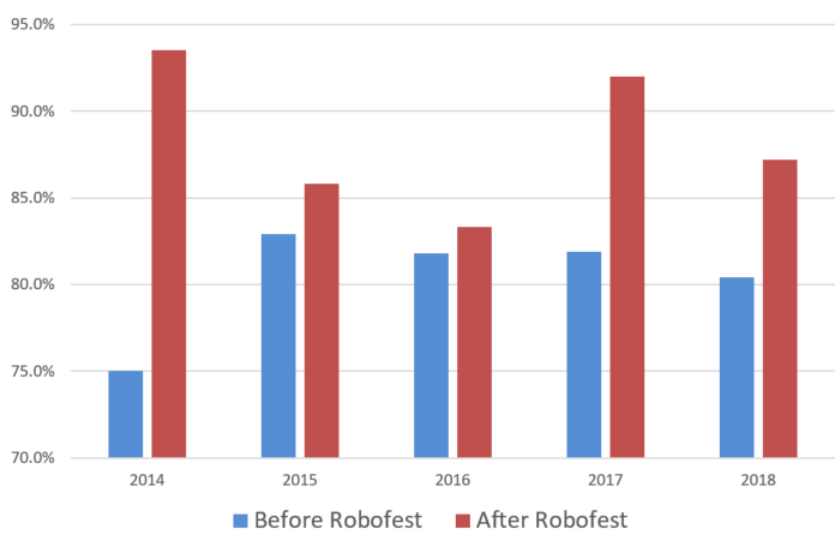

Figure 4. STEM career preference changes after participating in Robofest

\section{Future Objectives of Robofest}

In order to provide more effective hands-on and minds-on environment for STEM learning, Robofest sets the following objectives for the future.

We will pursue evidence-based education [6] by collecting \& analyzing more data on Robofest students' learning to determine which learning methods work best.

We will introduce the idea of competency-based learning [7] so that students will work on his/her own pace in learning STEM subjects through robotics. To implement this, we need to store data about each student's learning progress on our database system. This will allow us to introduce a new concept of competition - competition against past yourself. We will investigate to introduce new robotics platforms such as drones, legged robots, and mirco/nano robots. In addition, we will promote the integration of robotics with new technologies such as IoT (Internet of Things), Artificial Intelligence (AI), and Machine Learning (ML).

To strengthen Robofest organization, we will form advisory board consisting of Robofest coaches and notable alumni in robotics.

\section{Resumen en Español}

Robofest: un entorno de aprendizaje lúdico a través de la robótica autónoma

\section{Resumen}

Robofest [1, 2, 3] es una competencia de robótica autónoma en interiores centrada en el estudiante basada en los paradigmas PBL (aprendizaje basado en problemas) [4] y CBL (aprendizaje basado en competencia) [5]. Su misión principal es generar entusiasmo e interés entre los jóvenes por la Ciencia, Tecnología, Ingeniería y Matemáticas (STEM) a través de proyectos de robótica que integran materias STEM y Ciencias de la Computación. En segundo lugar, Robofest proporciona un entorno lúdico para que los estudiantes desarrollen habilidades de valor central bien redondeadas, como trabajo en equipo, liderazgo, creatividad/emprendimiento, comunicación y habilidades para resolver problemas. La tercera misión es preparar a los jóvenes para sobresalir en educación superior y carreras tecnológicas para el futuro.

\section{Palabras Claves:}

Robofest, Aprendizaje basado en problemas, Aprendizaje basado en competencias, STEM, STEaM, RoboParade, RoboArts, Desafío de misión desconocida, BotellaSumo, Desafío centrado en la visión, Juego.

\section{References}

[1] https://www.robofest.net, retrieved on 6-15-2019

[2] Chung, C., Cartwright, C., \& Cole, M. (2014). Assessing the Impact of an Autonomous Robotics Competition for STEM Education, Journal of STEM education, Vol 15, Issue 2, July-September 2014, pp. 24-34.

[3] Chung C., Cartwright C., DeRose J. (2017) Robotics Festival and Competitions Designed for STEM+C Education. In: Khine M. (eds) Robotics in STEM Education. Springer, Cham

[4] Hmelo-Silver, C.E. (2004). Problem-Based Learning: What and How Do Students Learn? Educational Psychology Review 16: 235.

[5] Chung, C. (2008 April) Learning through Competitions Competition Based Learning (CBL), LTU CTL Conference, https://www.robofest.net/LBA/CBL.pdf

[6] Wikipedia, Evidence-based education, https://en.wikipedia.org/wiki/Evidence-based_education, retrieved on 6-15-2019

[7] U.S. Department of Education, Competency-Based Learning or Personalized Learning https://www.ed.gov/oii-news/competencybased-learning-or-personalized-learning, retrieved on 6-15-2019

[8] Chung, C. (2014, March b), Integrated STEAM Education through Global Robotics Art Festival (GRAF), 4th IEEE Integrated STEM Education Conference (ISEC), March 8, 2014, Princeton University, $\mathrm{NJ}$

[9] Chung, C. \& Cartwright, C. (2014, Jan b). RoboParade: a Fun and Effective Way to Promote STEM Education, Proceedings of the 12th Hawaii International Conference on Education, Honolulu, Hawaii, Jan 5-9, 2014 